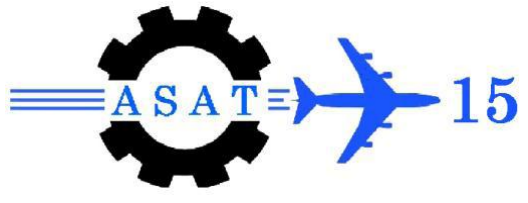

\title{
Effect of Slow-Active Suspension Controller Design on the Performance of Anti-Lock Brake System
}

\author{
A. M. Onsy ${ }^{*}$, A. M. Sharaf ${ }^{*}$, M. M. Ashry ${ }^{*}$ and S. M. Eldemerdash ${ }^{\S}$
}

\begin{abstract}
This paper presents an advanced integrated control system comprising the benefits of anti-lock brake system (ABS) and slow-active suspension system. A linear optimization technique is followed to improve the ride dynamics in terms of suspension working space, body vertical acceleration and tire dynamic normal load. The ABS controller regulates the applied barking pressure to maintain the tire skid ratio within the desired range. The presented investigation is applied to a quarter car model embracing an idealized limited bandwidth actuator in series with a suspension spring. This combination is further integrated with hydraulic circuit to modulate the braking pressure. The mathematical derivation is numerically solved using MATLAB package. Several simulation results are carried out considering typical performance measures such as stopping time, stopping distance and body vertical acceleration. The proposed design of the slow active suspension controller is suitable for both the ride vibration and brake performance which are widely applied in modern vehicles.
\end{abstract}

Keywords: Slow-active suspension, anti-lock braking system, vehicle dynamics and control.

\section{Nomenclature}

$A_{f} \quad$ Aerodynamic reference area $\left[\mathrm{m}^{2}\right]$

$B \quad$ Magic formula stiffness factor

$C_{d} \quad$ Vehicle aerodynamic drag coefficient

$C_{s} \quad$ Suspension damping coefficient [N.s/m]

$F_{d} \quad$ Aerodynamic drag force $[\mathrm{N}]$

$F_{s} \quad$ Passive suspension forces $[\mathrm{N}]$

$F_{t} \quad$ Dynamic tire forces $[\mathrm{N}]$

$F_{x} \quad$ Tire/road longitudinal friction forces $[\mathrm{N}]$

$F_{r} \quad$ Tire rolling resistance forces [N]

$F_{z} \quad$ Normal load [N]

$g \quad$ Gravity acceleration $\left[\mathrm{m} / \mathrm{s}^{2}\right]$

$I_{p}, J_{w} \quad$ Sprung mass and unsprung mass moments of inertia $\left[\mathrm{kg} . \mathrm{m}^{2}\right]$

$P_{a}, P_{d} \quad$ Actual and demand brake pressure values $\left[\mathrm{N} / \mathrm{m}^{2}\right]$

$R_{w} \quad$ Vehicle wheels dynamic radius [m]

\footnotetext{
* Egyptian Armed Forces, Egypt.

$\S$ Professor, Helwan University, Mataria, Cairo, Egypt.
} 


$\begin{array}{ll}u & \text { Active control force }[\mathrm{N}] \\ V & \text { Vehicle speed }[\mathrm{m} / \mathrm{s}] \\ \ddot{x}_{b} & \text { Vehicle braking deceleration }\left[\mathrm{m} / \mathrm{s}^{2}\right] \\ z_{o} & \text { Road displacement }[\mathrm{m}] \\ z_{b}, z_{w} & \text { Sprung mass and unsprung mass vertical displacements }[\mathrm{m}] \\ \rho & \text { Air density }\left[\mathrm{kg} / \mathrm{m}^{3}\right] \\ \mu & \text { Adhesion coefficient }[--] \\ \mu_{\mathrm{b}} & \text { Disk brake coefficient of friction }[--]\end{array}$

\section{Introduction}

Nowadays, a large number of computer controlled systems are widely employed in modern vehicles in order to improve their comfort, safety and directional stability. It has been noted that, each control algorithm is devoted for the purpose of performance optimization of an individual subsystem. For instance, the anti-lock brake systems (ABS) are designed to maintain the vehicle stability and to reduce the stopping distance during the braking process [1-2]. On the other hand, suspension controlled systems are introduced to improve ride comfort and road holding ability [3-10]. Hitherto, there is an increasing demand to integrate the automotive chassis with distinctive control systems for improving the overall dynamics of the vehicle.

Among the well-known related literature, Emam has presented a simple quarter car model comprising the dynamics of both vehicle ride and braking with ABS system [11]. Furthermore, he carried out several simulations to investigate the mutual significances between both systems. Later, Eldemerdash et al. have incorporated the control algorithm of a full active suspension system [12-13]. The suggested controller, reduced the stopping distance in comparison with the passively suspended vehicle with ABS.

The motivation of the presented research arises from the fact that the tire forces in longitudinal direction - either due to traction or braking - are fundamentally regulated by the available adhesion potential at the tire-ground contact patch. This potential is dependent upon the road friction $(\mu)$ and the tire imposed vertical force. Sequentially, this tire vertical force is predominantly restricted by its vertical oscillation which is highly controlled by the properties of the suspension system.

The presented paper exploits the aforementioned philosophy in favor of both ride and braking dynamics. For this purpose and based on initial work carried by Eldemerdash et al. [12-13], two approaches are presented, the first is considering a quarter car model with passive suspension and conventional braking systems. The second approach presents an integrated control system considering a quarter car model with slow-active controlled suspension and ABS braking system. This controller is designed based on the optimal control theory; taking into account changes in vehicle speed during the braking process. The suspension controller feedback gains are selected to minimize variations in tire-road normal forces and to control the pitch motion. The ABS controller is designed to control the slip ratio by a proportional directional valve with a time delay of $0.1 \mathrm{sec}$. 


\section{Suspension Controller Design}

A quarter car model is employed to correlate the vehicle ride dynamics due to vertical oscillations and the vehicle performance in the longitudinal direction due to the application of brakes as depicted in Fig. 1. The model consists of an unsprung or wheel mass $\left(m_{w}\right)$, which is connected to approximately a quarter of the vehicle's sprung mass $\left(m_{b}\right)$ by a spring and a damper system. In addition, a low bandwidth hydraulic actuator is placed in series with a suspension spring to actively damp the vertical chassis vibrations below the actuator bandwidth $(6 \mathrm{~Hz})$. The model possesses two degrees of freedom in vertical direction namely; the vertical displacement of the vehicle quarter body sprung mass $\left(z_{b}\right)$ and the vertical displacement of the wheel center $\left(z_{w}\right)$.

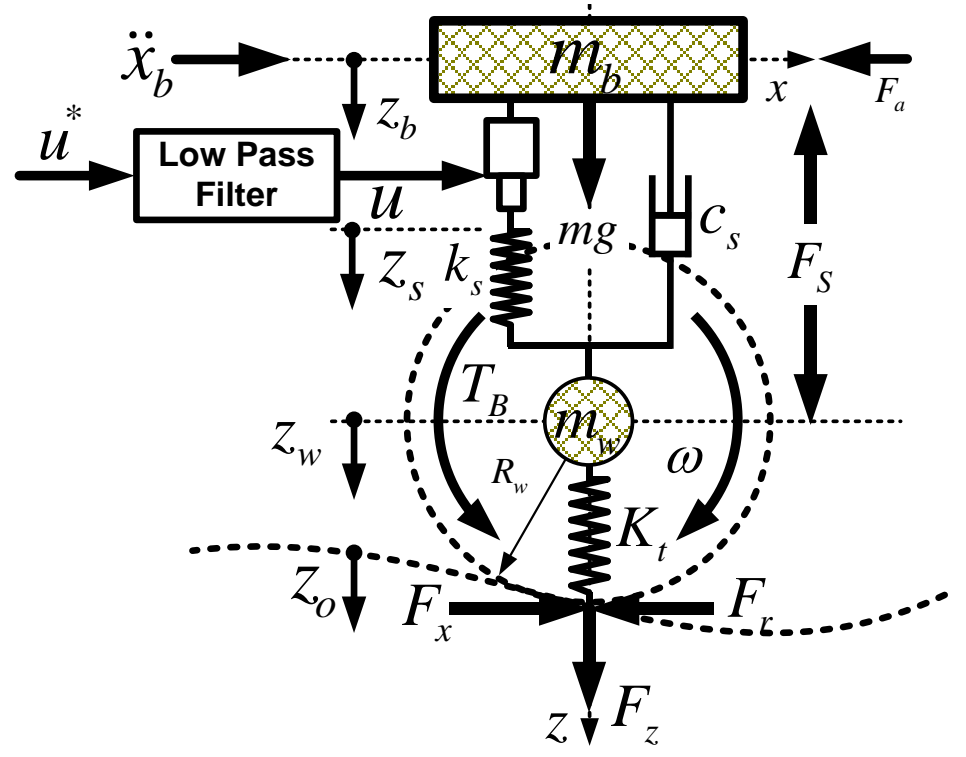

Fig. 1. Quarter Car Model with Slow Active Suspension System

A slow-active or low bandwidth suspension system aims to control the ride characteristics over the lower frequency range in particular around the rattle space frequency $(0: 6 \mathrm{~Hz})$. This system is introduced because of the significant reduction in body oscillations during cornering and braking maneuvers. In addition, it consumes lower power from the engine with cheaper components. The displacement generating actuator is considered to be ideal, i.e. the actuator instantly produces the displacement which is requested by the control signal $\left(u=z_{b}-z_{s}\right)$. The equations of motion in vertical direction can be derived by applying Newton's second law of motion for the vehicle body and wheel masses respectively as follow:

$$
\begin{aligned}
& m_{b} \cdot \ddot{z}_{b}=\underbrace{-k_{s} \cdot\left(z_{b}-z_{w}\right)-c_{s} \cdot\left(\dot{z}_{b}-\dot{z}_{w}\right)}_{F_{\text {suspension }}}+\begin{array}{r}
k_{s} \cdot u \\
F_{\text {Control }}
\end{array} \\
& m_{w} \cdot \ddot{z}_{w}=\underbrace{k_{s} \cdot\left(z_{b}-z_{w}\right)+c_{s} \cdot\left(\dot{z}_{b}-\dot{z}_{w}\right)}_{F_{\text {suspension }}}-k_{s} \cdot u-\underbrace{k_{t} \cdot\left(z_{w}-z_{o}\right)}_{F_{\text {Tontrol }}}
\end{aligned}
$$

All bandwidth limitations of the actuator are represented by a second order low pass filter desired control input deflection $\left(u^{*}\right)$ as follows: 
$\ddot{u}+\left(2 \zeta_{f} \omega_{c}\right) \dot{u}+\left(\omega_{c}^{2}\right) u=\left(\omega_{c}^{2}\right) u^{*}$

Where $\left(\omega_{c}\right)$ is the low pass filter's cut-off frequency and $\left(\zeta_{f}=1 / \sqrt{2}\right)$ is the low pass filter damping ratio. According to equations (1-3), the state space representation of the ride dynamics can be written as follows:

$[\dot{X}]=[A][X]+[B]_{1}[u]+[B]_{2}\left[z_{o}\right]$

$[Y]=[C][X]+[D]\left[z_{o}\right]$

where $[Y]$ is the output vector including the important quantities to be optimized e.g. body vertical acceleration, suspension working space and dynamic tire load. $[D]$ is a constant matrix and $[C]$ is the output constant matrix.

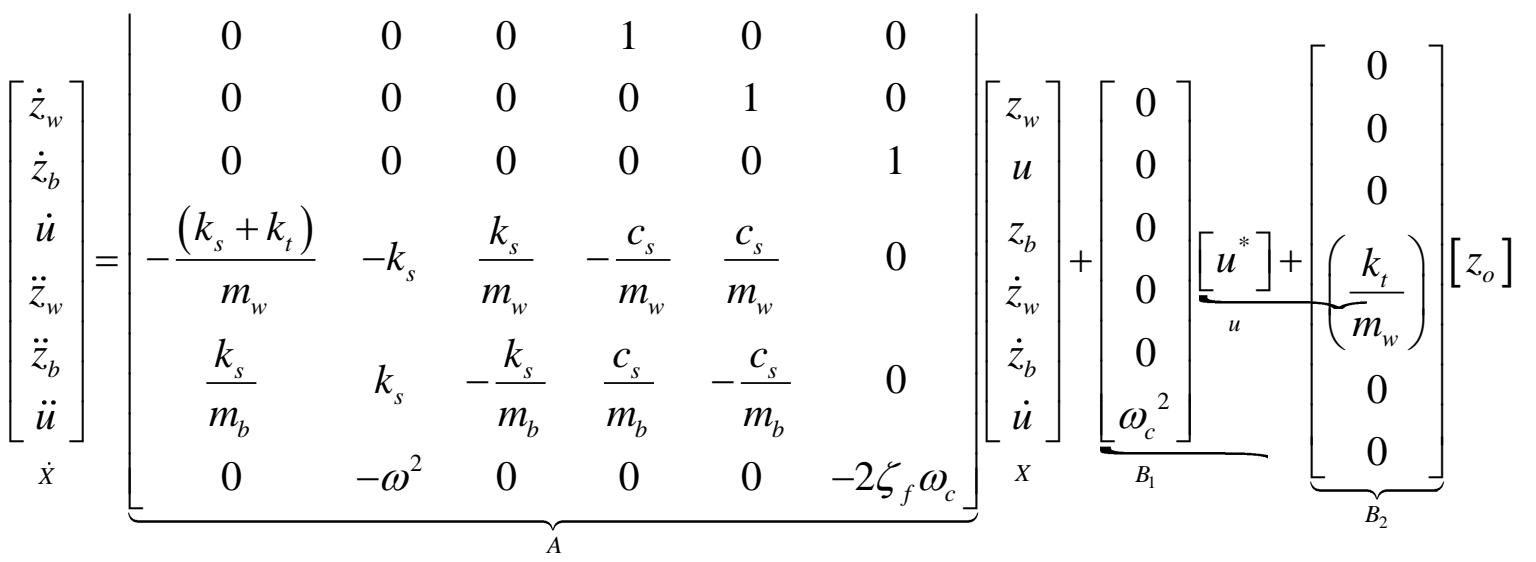

The inputs of the system are the actual displacement of the actuator $(u)$ and the state disturbance given by the vertical ground velocity $\left(\dot{z}_{o}\right)$. The ideal actuator assumption is such that the control signal (or reference displacement) is given by: $\left(u=z_{b}-z_{s}\right)$ where $\left(z_{s}\right)$ is actuator displacement. The outputs of the system are the vertical body acceleration, the suspension deflection, and the tire deflection. The new control input to the system becomes the desired actuator deflection $\left(u^{*}\right)$.

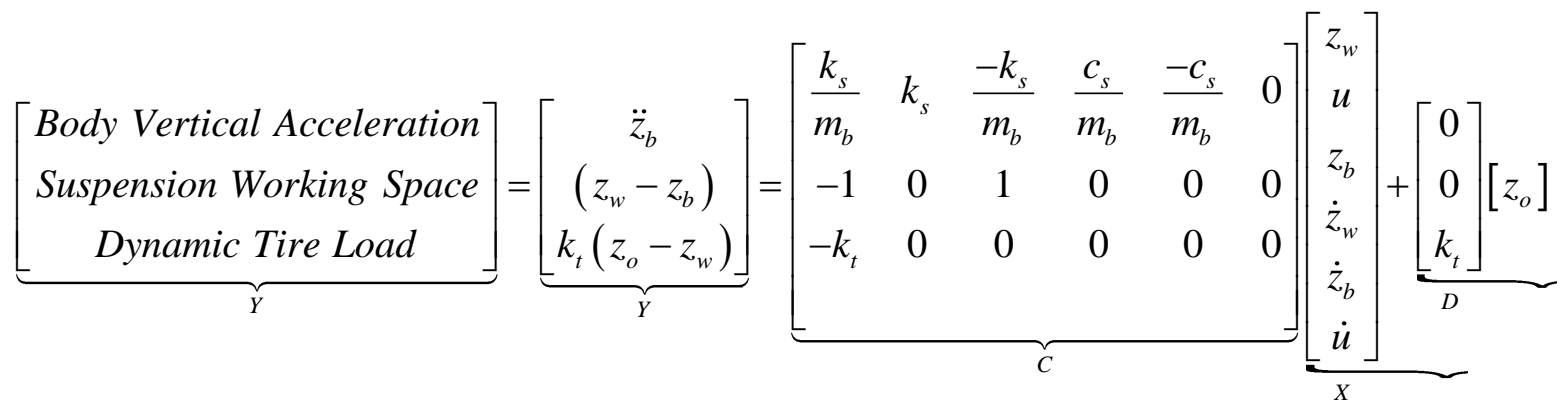


The derivation of a control law which optimizes system performance is an essential part of the design of any type of active suspension systems. The optimization goal is to minimize the vertical body acceleration and dynamic tire load, whilst at the same time maintain a suspension deflection within the allowable limits. The determination of the control law $(u(t))$ which minimizes the performance $(\mathrm{J})$ index is presented using the Stochastic Optimal Control Theory. A performance index is defined by the weighted sum of the integral square values for these outputs of interest as follows:

$$
J=\int_{0}^{\infty}(q_{1} \underbrace{\left(z_{w}-z_{b}\right)^{2}}_{\text {working space }}+q_{2} \underbrace{\left(z_{o}-z_{w}\right)^{2}}_{\text {Tire Deflection }}+q_{3}\left(\ddot{z}_{b}\right)^{2}+R u^{2}) \cdot d t
$$

where $\left(q_{1}, q_{2}, q_{3}\right.$ and $\left.R\right)$ are the weighting constants.

\section{Anti-lock Brake System Controller Design}

\subsection{The longitudinal Dynamics}

Considering the longitudinal dynamics of the vehicle, another two degrees of freedom are introduced namely; the vehicle displacement and the wheel angular rotation. The longitudinal dynamics of the vehicle body during braking can be derived by considering the tire brake force $\left(F_{x}\right)$ and the aerodynamic drag force $\left(F_{d}\right)$ as follow:

$$
\underbrace{\left(m_{b}+m_{w}\right)}_{\text {Total Vehicle Mass }} \cdot \ddot{x}_{b}=-F_{x}-F_{d}
$$

The aerodynamic drag force $\left(F_{d}\right)$ can be calculated as follow:

$$
F_{d}=\frac{1}{2} \rho \cdot C_{d} \cdot A_{f} \cdot \dot{x}_{b}^{2}
$$

where: $\left(\dot{x}_{b}\right)$ is the vehicle forward speed, $(\rho)$ is the air density, $A_{f}$ is the front projected area and $\left(C_{d}\right)$ is the aerodynamic drag coefficient and is assumed constant [13]. The rotational speed of the wheels $(\omega)$ during braking process can be derived using Newton's second law for rotational dynamics as follows:

$$
J_{w} \cdot \dot{\omega}=\left(F_{x}+F_{r}\right) \cdot R_{w}-T_{b}
$$

where $\left(J_{w}\right)$ is wheel moment of inertia including any drive-train effects, $\left(T_{b}\right)$ is the applied brake torque and $\left(F_{r}\right)$ is the rolling resistance which is given using the following equation [14]:

$$
F_{r}=\left(0.0136+0.4 \times 10^{-7} \times \dot{x}_{b}^{2}\right) \times F_{z}
$$

The tire vertical load $\left(F_{z}\right)$ is simply calculated as follows: 


$$
\underset{\text { Tire Vertical Load }}{F_{z}}=\underbrace{\left(m_{b}+m_{w}\right) \cdot g}_{\text {Tire Static Load }}+\underbrace{m_{b} \cdot \ddot{z}_{b}+m_{w} \cdot \ddot{z}_{w}}_{\text {Tire Dynamic Load }}
$$

From equations (9-10) and equation (11) the following equations are derived:

$$
\begin{aligned}
& \ddot{x}_{b}=\frac{1}{m_{b}+m_{w}}\left(F_{x}-\frac{1}{2} \cdot \rho \cdot C_{d} \cdot A_{f} \cdot \dot{x}_{b}^{2}\right) \\
& \dot{\omega}=\frac{1}{J_{w}}\left[\left(F_{x}+F_{r}\right) \cdot R_{w}-T_{b}\right]
\end{aligned}
$$

\subsection{The Tire Model}

The Pacejka's Magic Formula is used to estimate the barking force $\left(F_{x}\right)$ at the tire-ground contact patch, more details can be found in [14]. The formula relates the percentage of wheel slip $\operatorname{ratio}(S)$ and tire vertical force $\left(F_{z}\right)$ as follows:

$$
\begin{aligned}
& S=\left(1-\frac{\omega \cdot R_{w}}{\dot{x}_{b}}\right) \times 100 \% \\
& F_{x}=D_{m} \cdot \sin \cdot\left[C_{m} \cdot \tan ^{-1}\left(B_{m} \cdot S-E_{m} \cdot\left(B_{m} \cdot S-\tan ^{-1}\left(B_{m} \cdot S\right)\right)\right)\right]
\end{aligned}
$$

Where: $\left(C_{m}\right)$ is a constant, $\left(B_{m}, D_{m}, E_{m}\right)$ are functions of the tire $\operatorname{normal} \operatorname{load}\left(F_{z}\right)$ and slip ratio as follow:

Stiffness Factor: $\quad B_{m}=\frac{a_{3} \cdot F_{z}^{2}+a_{4} \cdot F_{z}}{C_{m} \cdot D_{m} \cdot e^{a_{5} \cdot F_{Z}}}$

Shape Factor: $\quad C_{m}=1.8$

Peak Factor: $\quad D_{m}=a_{1} \cdot F_{z}^{2}+a_{2} \cdot F_{z}$

Curveture Factor: $E_{m}=a_{6} \cdot F_{z}^{2}+a_{7} \cdot F_{z}+a_{8}$

where $\quad a_{1}$ to $a_{8}$ are typical constants which are given for a certain road surface as follows:

\begin{tabular}{c|c|c|c|c|c|c|c}
\hline \hline$a_{1}$ & $a_{2}$ & $a_{3}$ & $a_{4}$ & $a_{5}$ & $a_{6}$ & $a_{7}$ & $a_{8}$ \\
\hline-21.3 & 740 & 49.6 & 226 & -0.29 & -0.006 & 0.056 & 0.486 \\
\hline \hline
\end{tabular}


The tire braking force versus skid ratio is simulated for different roads with adhesion values as shown in Fig. 2-a and different tire vertical loads as shown in Fig. 2-b. It is obvious that, the potential of increasing the braking force at the tire ground contact area is reasonably increased with increasing road adhesion level as well as increasing the tire vertical load.

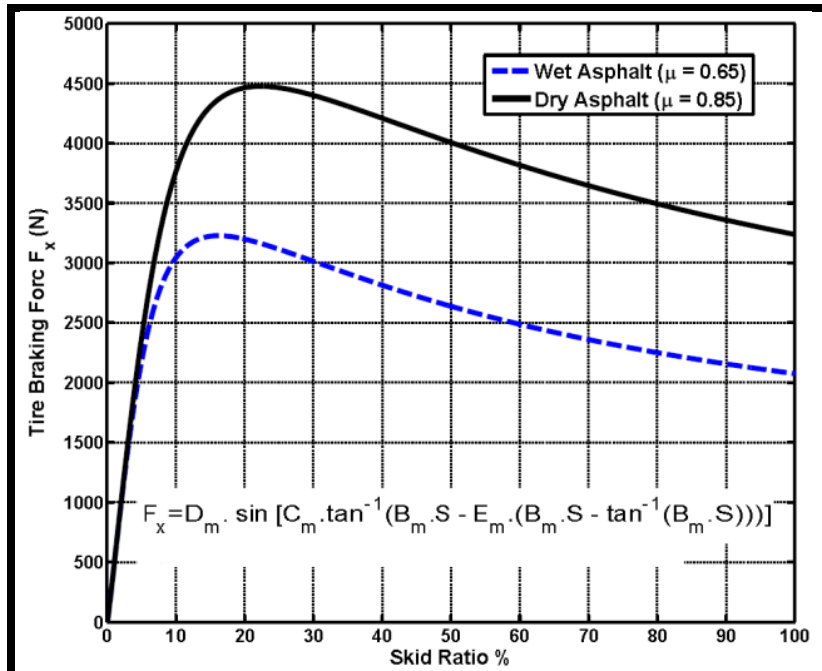

(a) Different values of adhesion

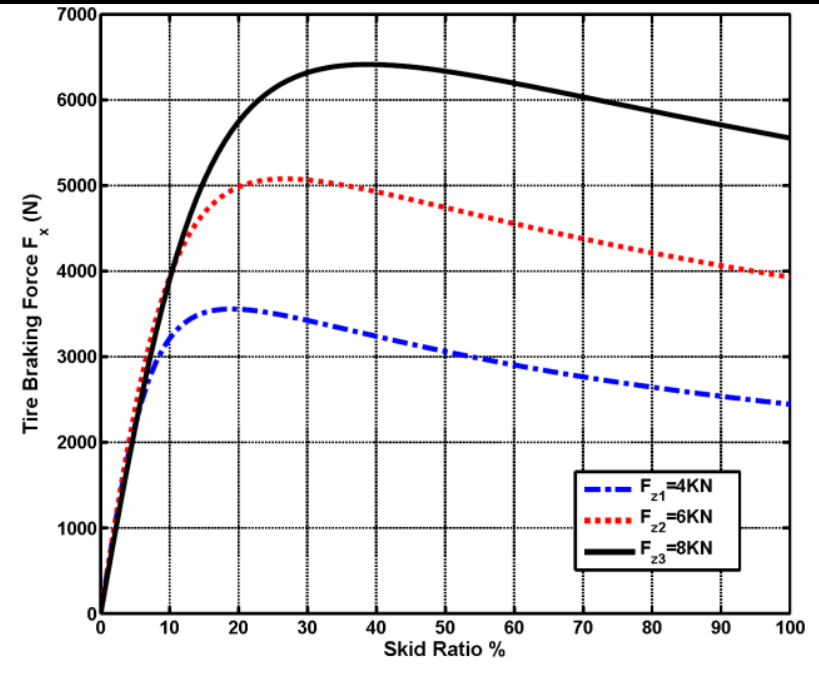

(b) Different values of tire vertical loads

Fig. 2. Tire Braking Forces Characteristics for Two Road's Conditions

\subsection{The ABS Controller}

The proposed control strategy combines a separate controller for the anti-lock brake system and a slow-active suspension system with a governing algorithm to coordinate the two controllers. Figs. 3-4 show schematic drawings for the integrated control system comprising a slow-active controlled suspension and hydraulic controlled ABS brake system. The fundamental function of the ABS control system is to regulate the friction utilization at the tire-ground contact area during braking process [1]. Accordingly, it prevents the tire from excessive skid particularly at higher braking forces. The tire skid ratio is limited by a desired value of $15 \%$ to maintain the peak braking force over different levels of road adhesion and tire vertical load as shown in Fig. 2. For the purpose of estimation of tire skid ratio, several sensors are incorporated to measure the associated variables such as deceleration and speed of the vehicle, deceleration and speed of the wheels, and hydraulic pressure of the brake fluid. The estimated skid ratio is then compared with the value of the desired skid ratio to produce an error signal as shown in Fig. 3. For each value of the error, the controller returns 1 if the value is greater than zero and hence the pressure is increased, returns 0 if the error equals zero and hence the pressure remains unchanged, and -1 if it is less than zero, and hence the pressure is reduced. On the other hand, according to the signal of the vehicle speed, the suspension controller modifies the feedback gains to minimize the fluctuations of tire normal force. 


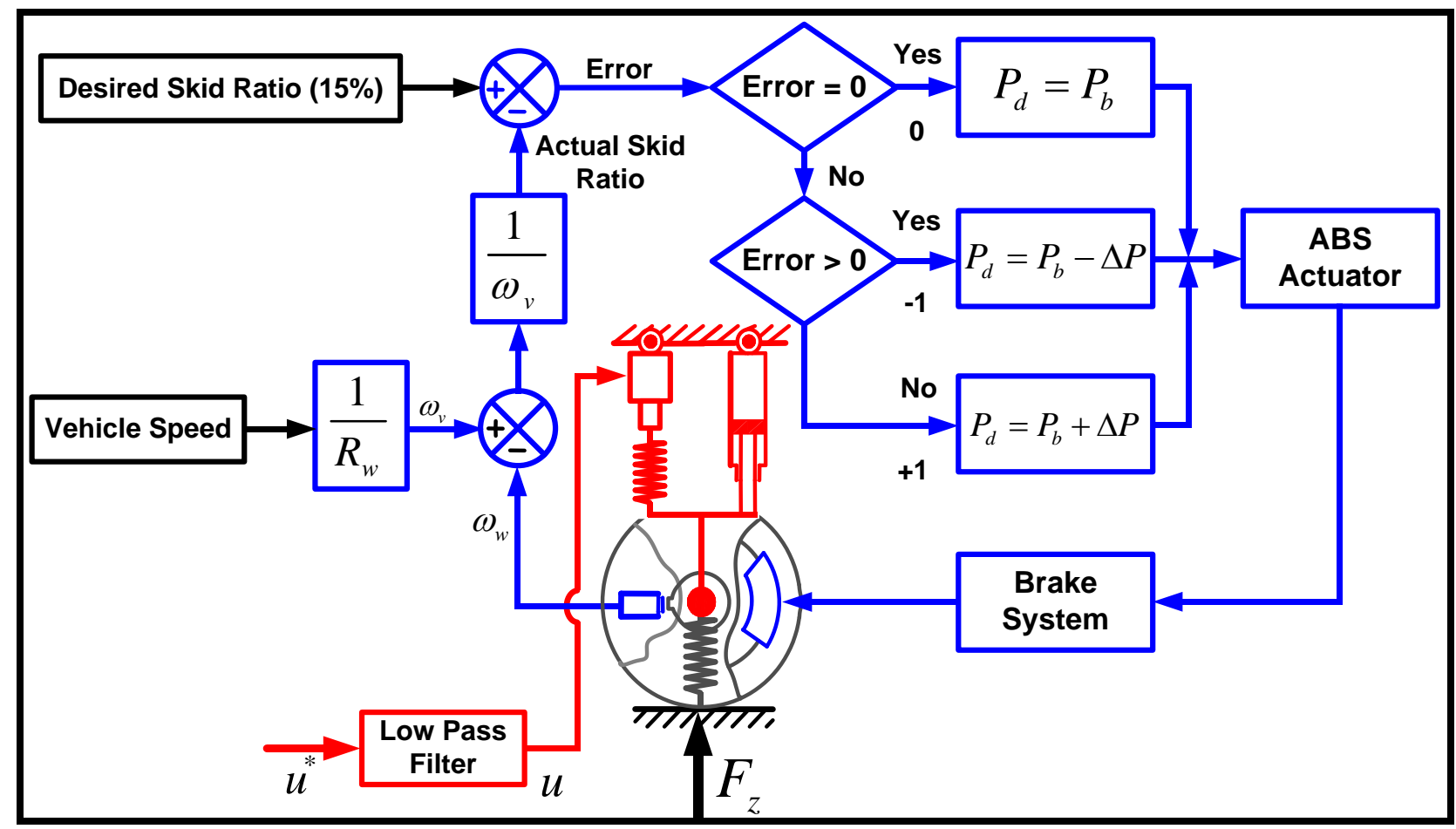

Fig. 3. Block Diagram for the ABS and Slow-active Suspension Controllers

According to the demand hydraulic pressure $\left(P_{d}\right)$, a proportional directional control valve is employed to modulate the hydraulic brake pressure $\left(P_{a}\right)$ as shown in Fig. 4. The directional control valve is modeled as a first order differential equation with a time delay $(t)$ as follows:

$$
\dot{P}_{a}+\left(\frac{1}{t}\right) P_{a}=\left(\frac{1}{t}\right) P_{d}
$$

The resulting brake torque $\left(T_{b}\right)$ can be calculated as is a linear function of the brake pressure $\left(P_{a}\right)$, the area of the wheel cylinder $\left(A_{w c}\right)$, the disk brake lining friction coefficient $\left(\mu_{b}\right)$, the effective disk brake radius $(r)$ and the number of friction surface $\left(n_{S}\right)$ :

$$
T_{b}=\underbrace{P_{a}^{P_{a} \cdot A_{w c}} \cdot \mu_{b} \cdot n_{s}}_{\text {Brake System Force }} \cdot r
$$




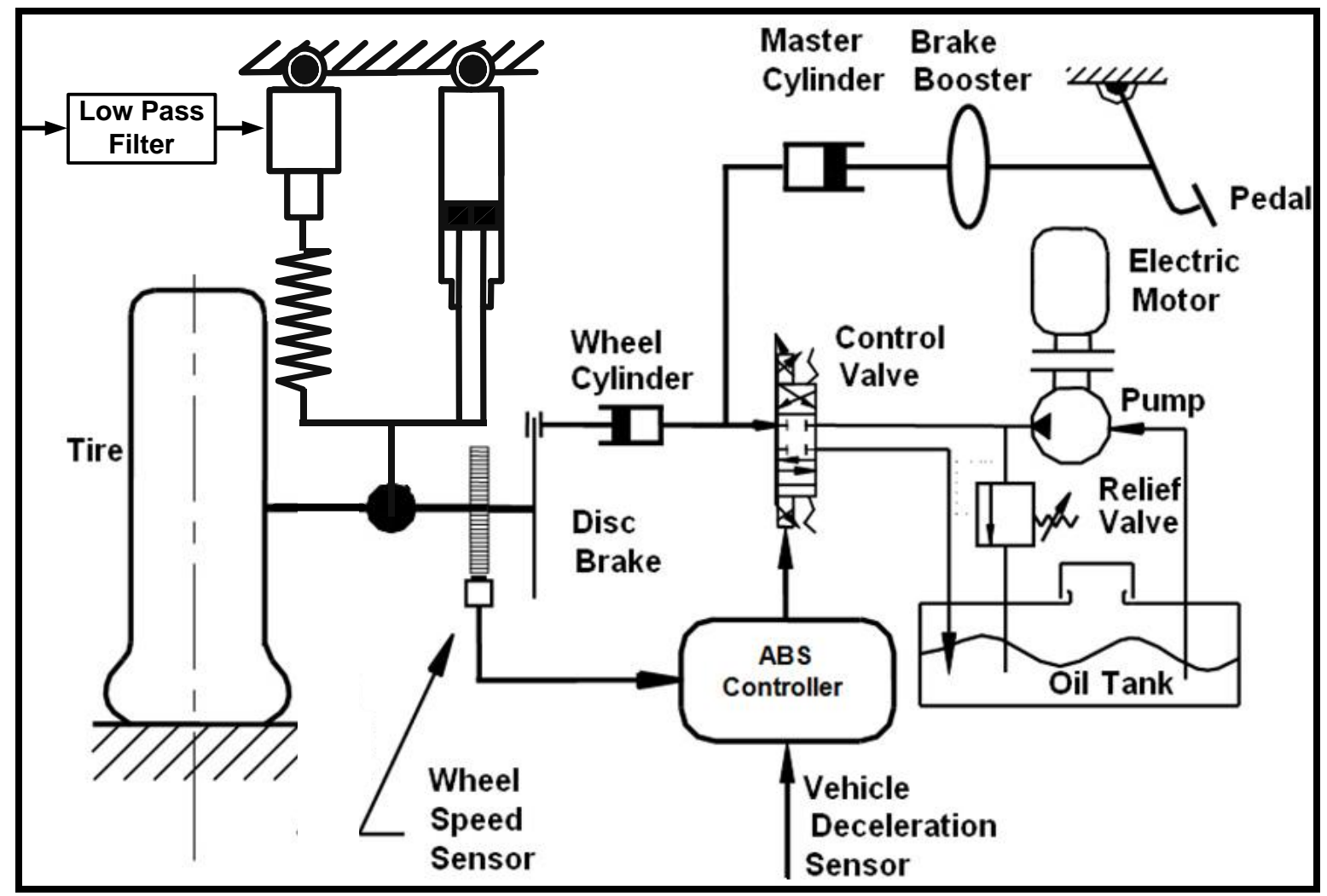

Fig. 4. Schematic Drawing of the Integrated Controller System

\section{Results and Analysis}

The derived integrated control algorithm as well as the proposed optimization technique is implemented using the MATLAB package. For the purpose of performance comparison, several simulation results have been reported incorporating the conventional barking system, Anti-Lock Braking system, passive suspension system and slow-active suspension system. For the braking performance evaluation, several measures are used such as the vehicle forward speed, the wheel rotational speed, the braking pressure, the tire skid ratio, the tire normal force, the friction force, the vehicle deceleration and finally the stopping distance. Other important results such as the effect of the road roughness coefficient and the coefficient of adhesion on the braking performance are also considered for both systems. In carrying out these calculations, the numerical values of the vehicle main parameters are used and given in appendix I.

The results of simulation are illustrated in Figs. 5 to 7 . The initial speed of the vehicle is 100 $\mathrm{Km} / \mathrm{hr}(27.8 \mathrm{~m} / \mathrm{s})$ and the brake pedal is applied while driving on a wet road with minor roughness coefficient $\left(R_{c}=5 \times 10^{-6}\right)$. Primarily, the effect of controlled suspension, passive or slow-active, is considered without application of ABS on a wet road surface as shown in Fig. 5-a. While the vehicle demands six and half seconds to reach to full stop, the wheel locks up and stops spinning in less than one second and half. This occurs with little difference whether the vehicle is passively or actively suspended. 

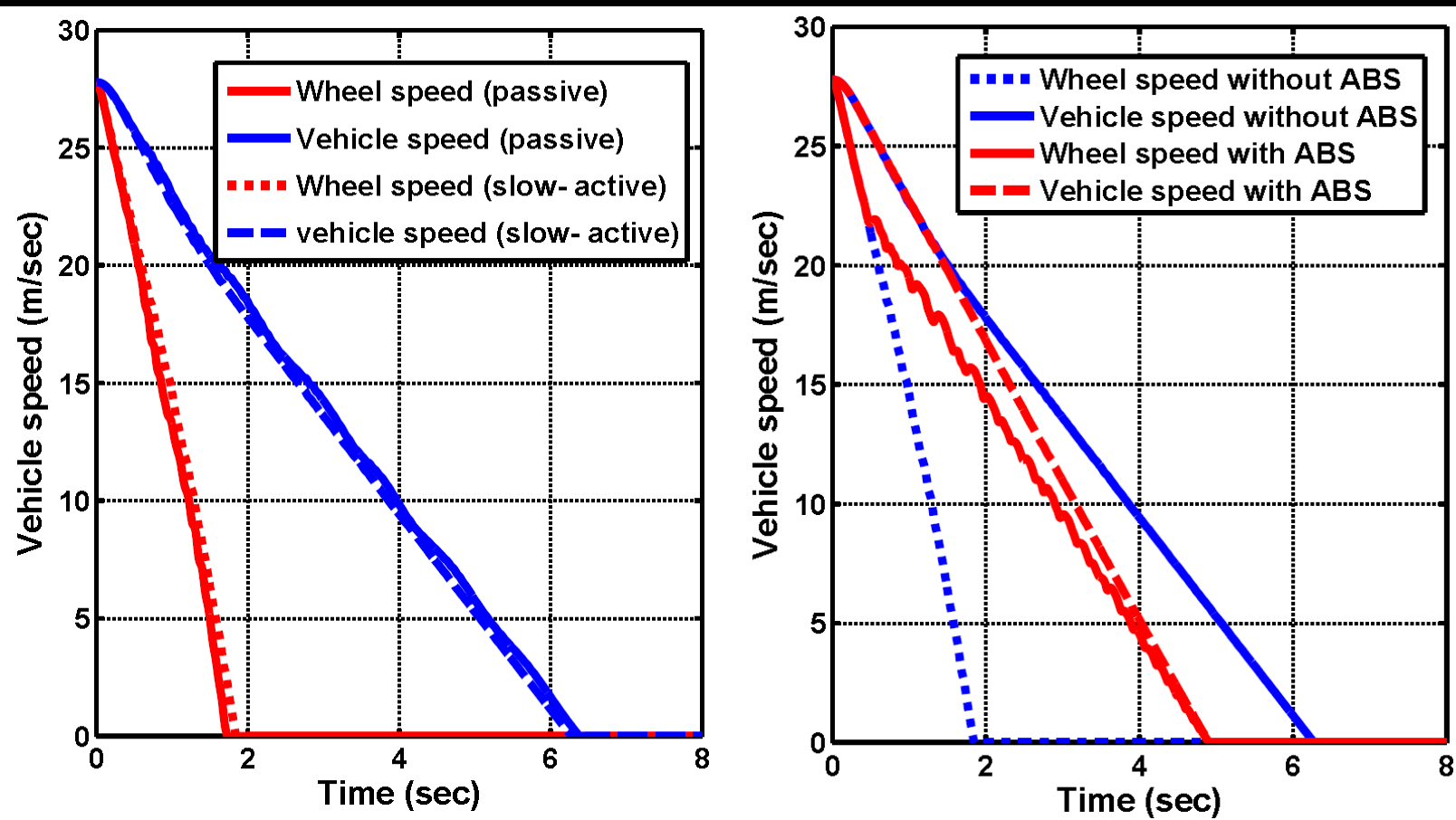

(a) Effect of suspension control without ABS

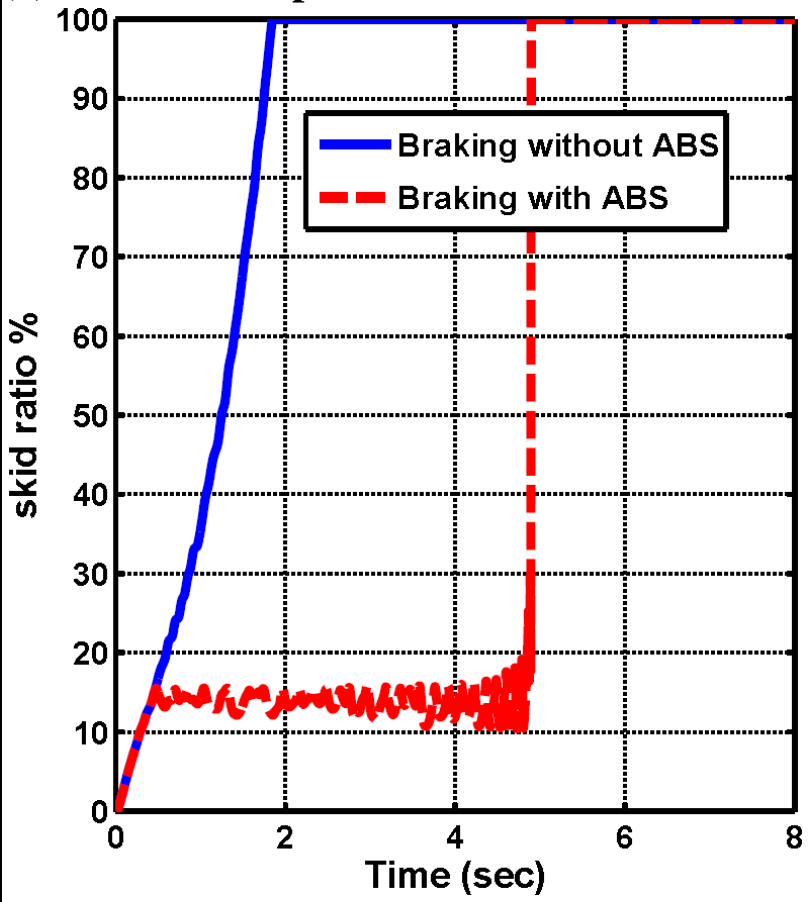

(c) Skid percentage

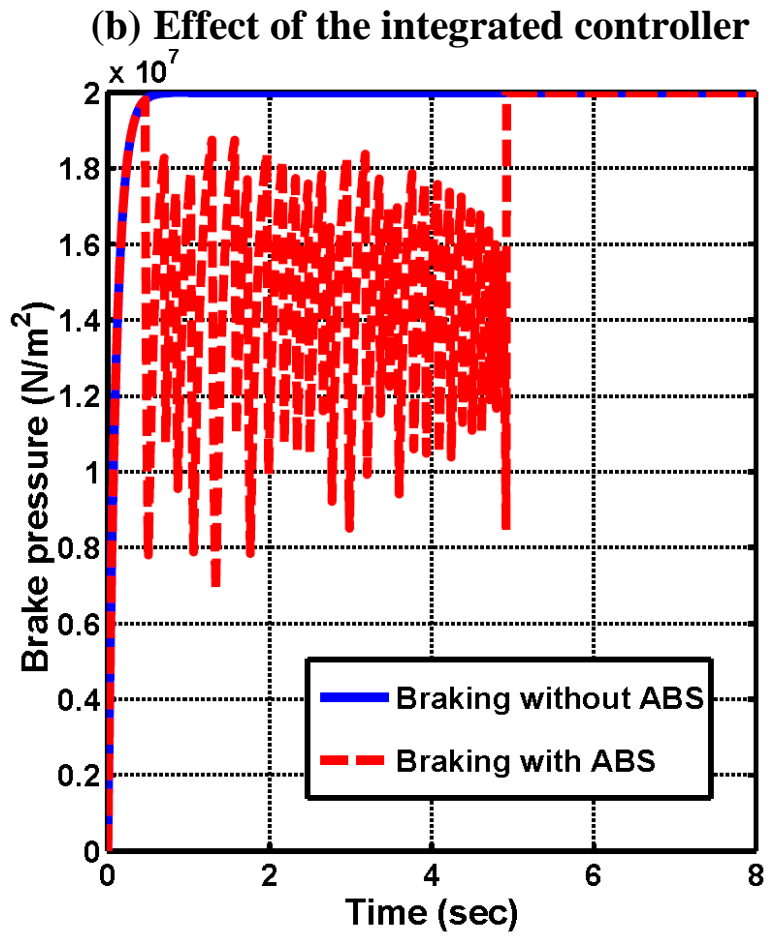

(d) Brake system pressure

Fig. 5. Results of the ABS Fitted to the Actively Suspended Vehicle

On the other hand, the result of implementing the integrated controller, ABS and slow-active suspension system, reveals an improved stopping time as shown in Fig. 5-b. The integrated controller monitors both vehicle and wheel rotational speed sensors at all times. Therefore, it regulates the braking pressure to the wheel cylinder up and down, Fig. 5-d, according to the desired skid ratio as shown in Fig. 5-c. As a result, the wheel is prevented to excessively lock-up and thus decelerates at similar rate to the vehicle body. A comparison between the integrated system and the slow active system without ABS are indicated in terms of the stopping time and the stopping distance as shown in Table (1). 
Table (1) A comparison between the integrated system and the slow active system without ABS

\begin{tabular}{l|c|c}
\hline \hline & Stopping time $(\mathrm{s})$ & Stopping distance $(\mathrm{m})$ \\
\hline \hline Slow active suspension without ABS & 6.4 & 85.4 \\
\hline Integrated ABS and Slow active systems & 4.9 & 70.3 \\
\hline \hline
\end{tabular}

To investigate the improvements afforded by the proposed system, Fig. 6 illustrates the outcomes of implementing the integrated control system in comparison to a conventional ABS fitted with a passively suspended vehicle. The evaluation is carried out in terms of the tire normal and friction forces, the vehicle deceleration and the stopping distances for both systems.

In comparison to the passive suspension system, it should be noted that, the controller design takes into consideration the minimization of the tire dynamic load variation as well as the vertical acceleration of the vehicle sprung mass. This effect can be obviously recognized from Fig. 6-a, where the slow-active suspension reduces significantly both the fluctuations and the range within which tire normal force is oscillating. In turn, the reduction of dynamic tire load has a direct effect on the tire friction force in a similar way as shown in Fig. 6-b.

The same analysis can be followed to reveal the benefits of slow-active suspension system to minimize the vehicle deceleration as shown in Fig. 6-c and reduce the stopping distance by around 5\% as shown in Fig. 6-d.

It is a prime of interest to examine the benefits that could be achieved from the integrated control system for different road conditions such as; various road roughness coefficients and various coefficients of adhesion as shown in Fig. 7. Considering the same road roughness coefficient, the stopping distance is reduced during braking on a dry asphaltic road than that achieved during braking on wet asphaltic road. This is principally due to the higher adhesion coefficient which in turn improves the potential of application greater barking force and thus higher deceleration and smaller stopping distance.

Further reduction in the stopping distance can be offered by implementing the slow-active controller due to the reduction of the dynamic tire load as mentioned before. For the same road and suspension design conditions, increasing the road roughness coefficient refers to coarser roads which promote more dynamic tire load variation and increasing the braking stopping distance. 


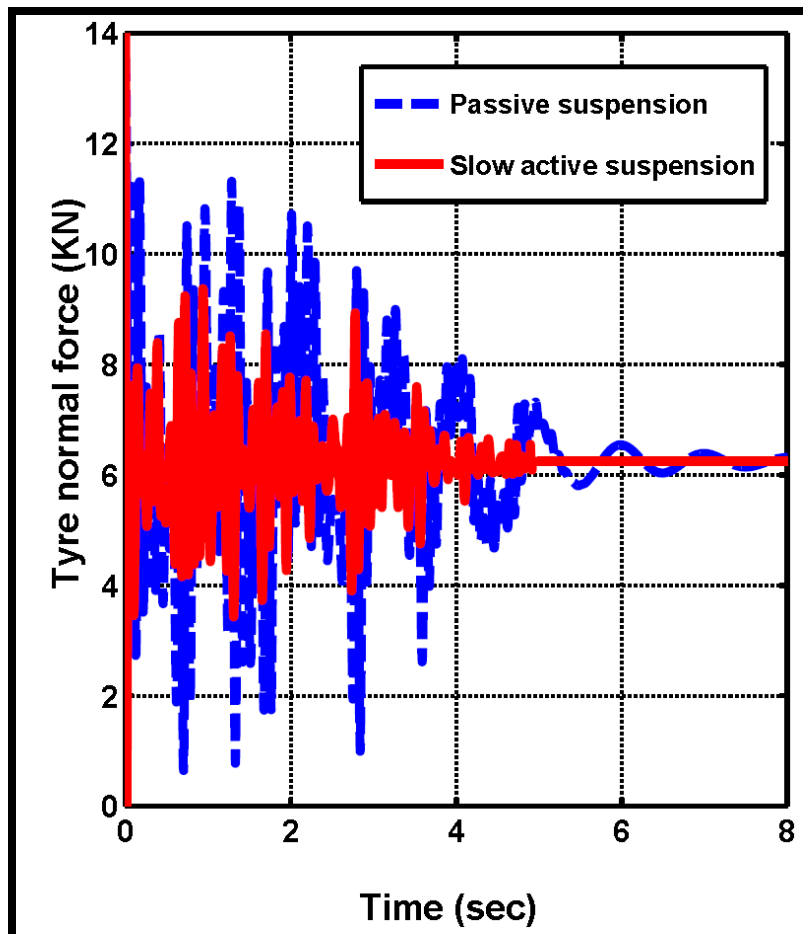

(a) Tire normal force

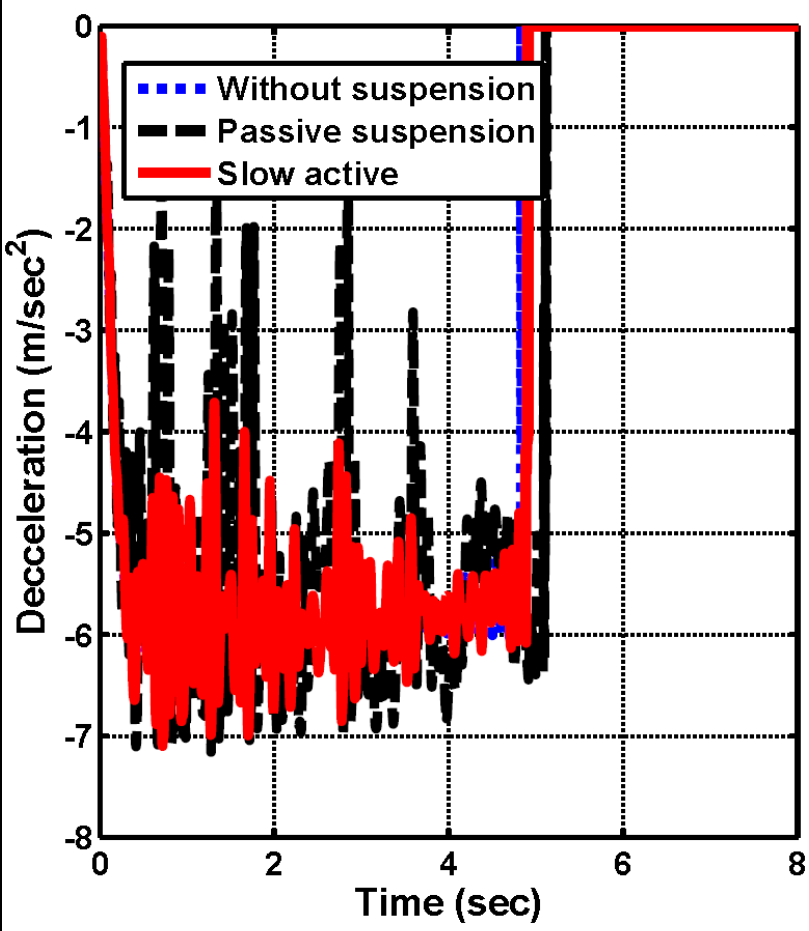

(c) Vehicle braking deceleration

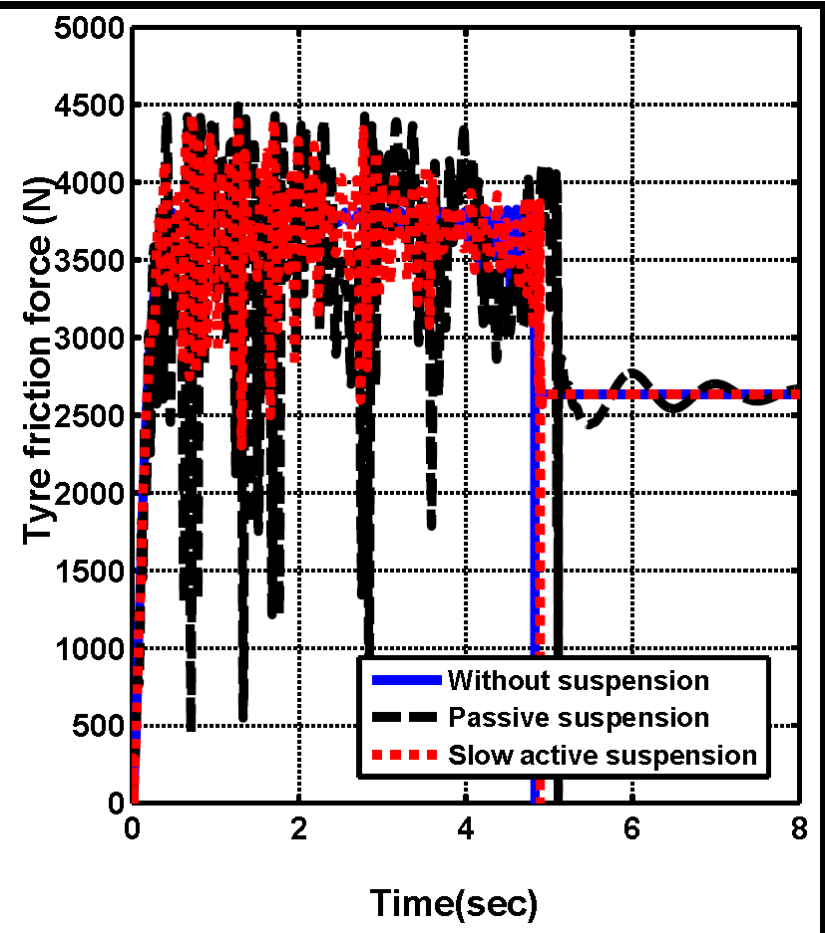

(b) Tire friction force

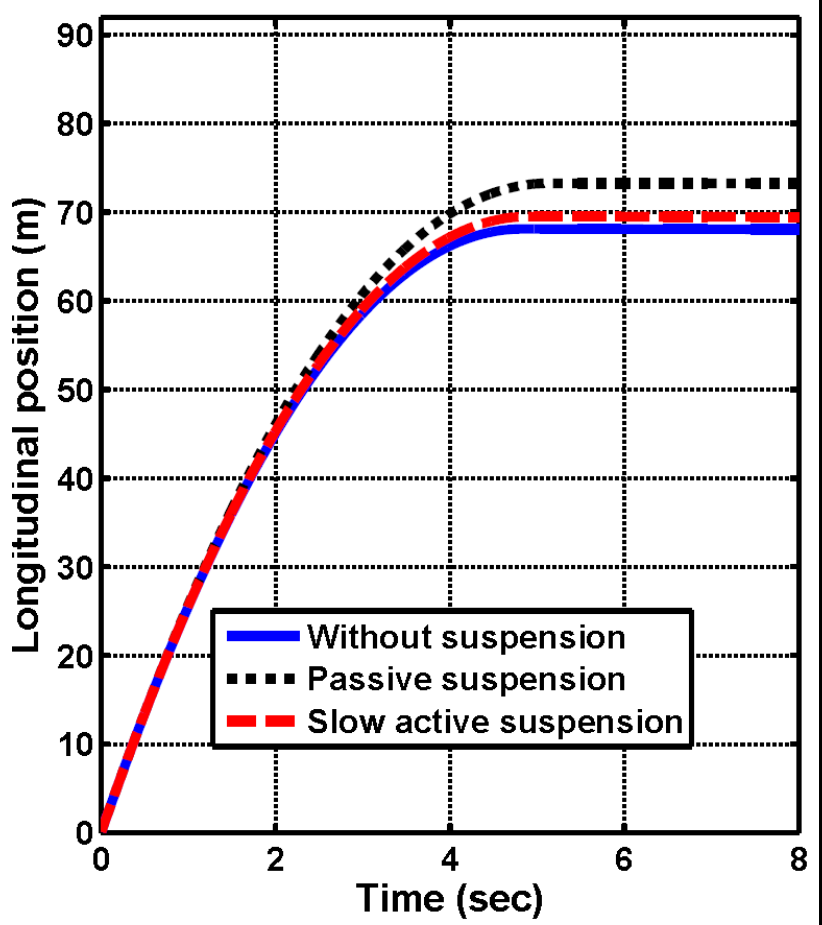

(d) Covered distance during braking

Fig. 6. ABS Plus Slow Active Suspension Against ABS Plus Passive Suspension 

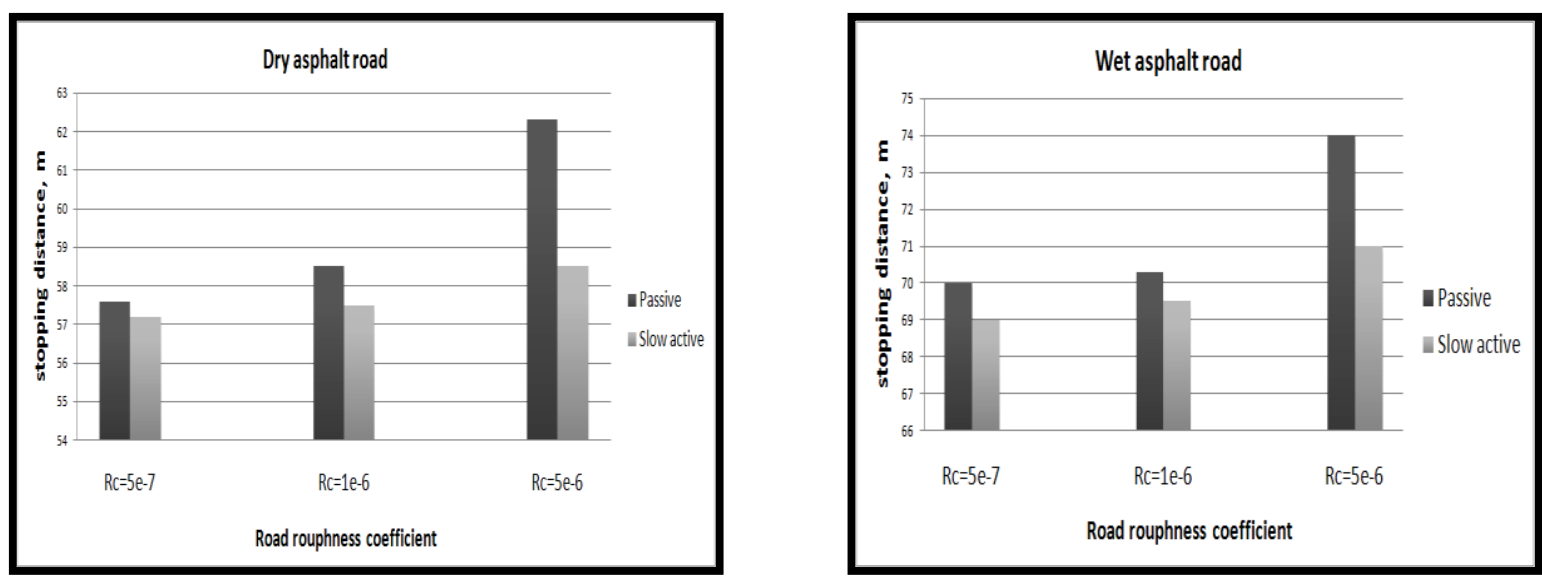

Fig. 7. Effect of Road Roughness and Adhesion Coefficients on the Stopping Distance

\section{Conclusions}

A mathematical formulation has been derived to correlate the ride dynamics and the braking dynamics considering a simplified quarter car model. The conflict between both systems dynamics arises from the applied dynamic normal load at the tire-ground contact area. An integrated control strategy with optimization technique is proposed to maximize the barking force and to minimize the dynamic tire load, suspension working space and body vertical acceleration. For this purpose, two integrated controllers are combined namely; a slow-active suspension controller is combined with anti-lock braking system controller. It has been illustrated that, the integrated controller reduces the stopping distance either for dry or wet road surface in comparison with the ABS system fitted solely to a passively suspended vehicle.

\section{References}

[1] Sugai, M., Yamaguchi, H., Miyashita, M., Umeno, T. and Asano, K., "New Control Technique for Maximizing Braking Force on Anti-Lock Braking System", AVEC98, 1998.

[2] Jun, C., "The Study of ABS Control System with Different Control Methods", AVEC98, 1998.

[3] Hong, K.S., Sohn, H.C., and Hedric, J.K., "Modified Skyhook Control of Semi-Active Suspensions: A New Model, Gain Scheduling, and Hardware-in-the-loop Tuning", Transactions of the ASME, Vol. 124, March, 2002.

[4] Abdelhady, M.B.A. and El-demerdash, S.M., "Adaptive Control Strategy of a Kalman Filter Active Vehicle Suspensions", SAE Paper No. 2003-01-1413, International Noise and Vibration Conference \& Exhibition, Traverse City, Michigan, USA, 2003.

[5] Abdelhady, M.B.A., "Aerodynamic Effects on Ride Comfort and Road Holding of Actively Suspended Vehicles", SAE Paper No. 2002-01-22025, 2002.

[6] El-demerdash, S.M., "A Hydro-Pneumatic Suspension System for Passenger Cars", $11^{\text {th }}$ International Mechanical Power Engineering Conference (IMPEC11), Egypt, 2000.

[7] El-demerdash, S.M., "Performance Tradeoffs in Control Design for Automotive Active Suspensions ", $3^{\text {rd }}$ International Conference on "Total Vehicle Technology", IMechE, England, April 2004. 
[8] Koch, G., Fritsch, O. and Lohmann, B., "Potential of Low Bandwidth Active Suspension Control with Continuously Variable Damper", Institute of Automatic Control, Technical University, Munchen, D-85748 Garching, Germany, Proceedings of the $17^{\text {th }}$ World Congress, The International Federation of Automatic Control, Seoul, Korea, July 6-11, 2008.

[9] Xin, Z. and Jianwu, Z., "Performance Analysis of Limited Bandwidth Active Suspension with Preview Based on a Discrete Time Model", School of Mechanical Engineering, Shanghai Jiaotong University, 800 Dongchuan Road, Min Hang, Shanghai, 200240, P. R. China, 2010.

[10] ElMadany, M.M., "Control and Evaluation of Slow-Active Suspensions with Preview for a Full Car" Mechanical Engineering Department, King Saud University, P.O. Box 800, Riyadh 11421, Saudi Arabia, 2011.

[11] Emam, A.S., "Electronically Controlled Vehicle Brake Systems", MSc Thesis, Automotive and Tractors Engineering Department, Faculty of Engineering at Mataria, Helwan University, 2002.

[12] El-demerdash, S.M., "An Integrated Control for Vehicle Active Suspension and Anti-Lock Brake Systems “, Engineering Research Journal 92, University of Helwan, Egypt, April 2004.

[13] El-demerdash, S.M., Abdelhady, M.B., Alnashar, M.A. and Emam, A.S., "Effect of Vehicle Suspension Control on the Performance of Anti-Lock Brake Systems", IMechE International Conference on Braking Technology, St William's College, York, May 7-9, 2006, UK.

[14] Wong, J.Y., “Theory of ground vehicles”, 4 ${ }^{\text {th }}$ ed., Hoboken, N.J., Wiley, 2008.

Appendix (I) The main parameters of the quarter car model and the ABS

\begin{tabular}{l|c|l|l}
\hline \multicolumn{1}{c|}{ Parameter } & Symbol & Value & \multicolumn{1}{c}{ Unit } \\
\hline \hline Quarter of the vehicle body or sprung mass & $m_{b}$ & 578 & {$[\mathrm{~kg}]$} \\
\hline Unsprung masses & $m_{w}$ & 58.25 & {$[\mathrm{~kg}]$} \\
\hline Engine and wheel moments of inertia & $J_{w}$ & 13.7 & {$\left[\mathrm{kgm}^{2}\right]$} \\
\hline Passive spring stiffness coefficients & $K_{s}$ & 25 & {$[\mathrm{kN} / \mathrm{m}]$} \\
\hline Passive damping coefficients & $C_{s}$ & 1 & {$[\mathrm{kNs} / \mathrm{m}]$} \\
\hline Tire vertical stiffness coefficients & $K_{t}$ & 255 & {$[\mathrm{kN} / \mathrm{m}]$} \\
\hline Vehicle aerodynamic frontal area & $A_{f}$ & 2.04 & {$\left[\mathrm{~m}^{2}\right]$} \\
\hline Vehicle aerodynamic drag coefficient & $C_{d}$ & 0.539 & {$[--]$} \\
\hline Wheel cylinder piston radius & $r_{p}$ & 0.0185 & {$[\mathrm{~m}]$} \\
\hline Tire dynamic radius & $R_{w}$ & 0.273 & {$[\mathrm{~m}]$} \\
\hline Front and rear lining coefficient of friction & $\mu_{b}$ & 0.35 & {$[--]$} \\
\hline \hline
\end{tabular}

